\title{
ENTERIJER UGOSTITELJSKOG KOMPLEKSA U GRADU KOLONIJA DE SANT PERE NA MAJORCI
}

\section{INTERIOR DESIGN OF A CATERING BUILDING IN THE CITY OF COLONY DE SANT PERE IN MAJORCA}

\section{Ivana Šanjević, Fakultet tehničkih nauka, Novi Sad}

\begin{abstract}
Oblast - ARHITEKTURA
Kratak sadržaj - Bilo je neophodno enterijer vile $i$ kafeterije uskladiti sa nekim postojećim materijalima $i$ elementima, kao i nameštajem, koji su zadržani zarad očuvanja autentičnog duha objekta, ali su zadržani na takav način da ih je bilo moguće dalje kombinovati sa modernim stilom. Nova fukcija objekta morala je biti proizvod skladnog sklopa i jasne celine cele vile, a za to je bilo potrebno osmisliti dobro rešenje, kako bi cela kompozicija projekta bila jasna i definisana.
\end{abstract}

Ključne reči: Enterijer, uređenje vile $i$ kafeterije, socijalizacija, rasveta, obrada podova

\begin{abstract}
An interior of the villa and cafeteria needs to be harmonized with the materials, elements and furniture inside it, which are preserved in order to keep authenticity of the object. Later, it was possible to combine all those things in a modern manner. New purpose of the objcet had to be the result of a good solution for the composition of the project. Everything had to be perfectly clear and defined.
\end{abstract}

Keywords: Interior, arrangement of the villa and cafeteria, socialization, lighting, flooring

\section{UVOD}

Cilj je bio osmisliti novi enterijer, ali bez gubitka istorije $i$ duha datih prostorija. U njemu je trebalo očuvati već postojeće dekoracije i predmete u kući; tako su, na primer očuvane grede u zateknutom stanju, postojeći prozori i vrata, kao i kameni pod. Autentična atmosfera se još održala restauracijom starog nameštaja. Kuhinjsku prostoriju trebalo je bolje organizovati, i trebalo je osmisliti sobu za druženje. Zapravo, trebalo je iskombinovati rustične elemente sa minimalističkim stilom. Pritom, važno je da istraživanjem dođemo do enterijera $u$ kome će se posetioci osećati ugodno i prijatno.

\section{OBLAST ISTRAŽIVANJA}

Enterijer svake prostorije uređivan je tako da se prepliću hladni i topli materijali. Beton kao glavni predstavnik hladnih materijala parira drvetu i drvenom nameštaju koji pogoduje svakom stilu i može preuzeti jedinstvene forme dizajnirane kako bi svaki prostor učinile lepšim i prijatnijim.

S obzirom na to da je Španija više vekova bila pod uticajem islamskog sveta, nije čudo da je sve to ostavilo svoj trag na tom prostoru, kao, na primer, u Granadi, gde objekti izgledaju kao kuće od peska. To znači da se zid, plafon i pod stapaju po bojama i teksturi i slivaju u jednu celinu. U ovoj prostoriji primarna je završna obrada zidova. Posebno se vodilo računa o birnjau obloga i detaljima koji su služili da se zadrži duh kuće, ali ipak n apravi novi enterijer.

\section{PRISTUP TEMI}

Uvidom u primere enterijera vila „Kalos”, „La Kvinta”, „Olivi”, i restorana „mama Fo”, došlo se do zaključka da je važno napraviti prijatnu atmosferu i ambijent za njene posetioce. Na prvom mestu važne su lokacije ovih vila, kao njihova okolina, upravo zarad maksimalnog odmora. Vrlo je poželjno da vile imaju propratne sadržaje na samom imanju na kom se nalaze, primera radi, bazene, bašte, uređene travnjake, otvorene letnje kuhinje i slično, slika 1.

Unutrašnjost ovih vila mora parirati njihovoj spoljašnjosti, pa se tako unutra moraju naći prirodni materijali, tople boje i tonovi.

Igra svetlosti i senke mora biti u potpunoj ravnoteži i ništa ne treba previše da odvlači pažnju gostima ovakvih kuća, već je neophodno da svaki detalj upotpuni mir i odmor gostiju, slika 2 .

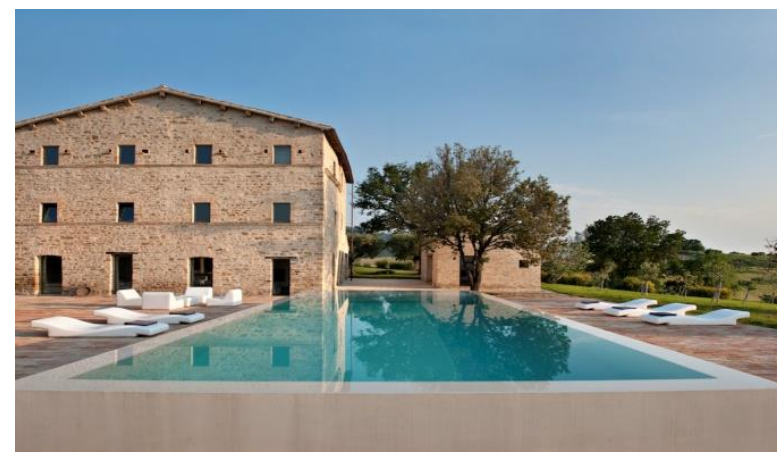

Slika 1: Prikaz eksterijera vile „,Olivi” [1]

\section{NAPOMENA:}

Ovaj rad proistekao je iz master rada čiji mentor je bila dr Ivana Miškeljin, red. prof. 


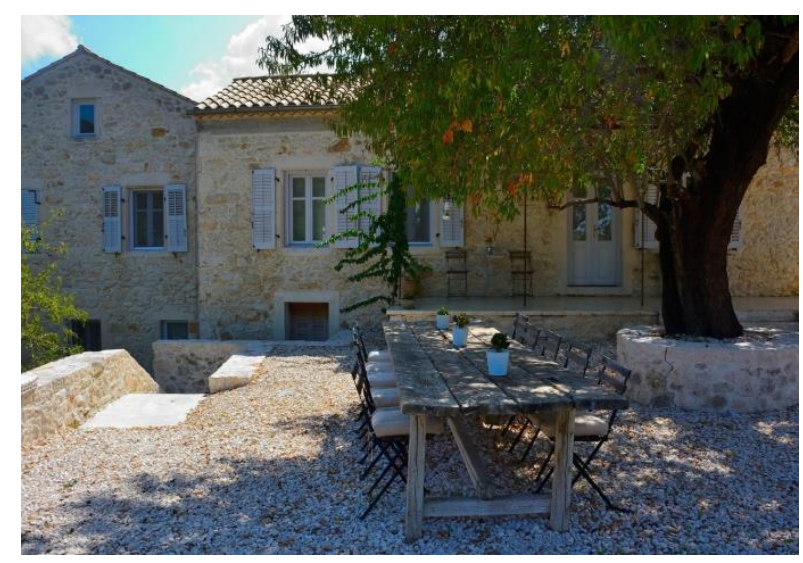

Slika 2: Prostrano dvorište vile „Kalos” [2]

\section{PROCES PROJEKTOVANJA}

Obzirom da je prvenstvena namena objekta odmor i relaksacija gostiju koji dolaze u potrazi za odmorom od gradova i ubrzanog načina života, na prvom mestu je bitno odabrati lokaciju vile koja će biti dovoljno udaljena od grada ali i dovoljno blizu. Njihova okolina treba da bude ugodna za posmatranje, jer vreme provedeno ovde treba sporije da teče. Iz tog razloga je poželjno da vile imaju propratne sadržaje na samom imanju na kom se nalaze, primera radi, bazene, bašte, uređene travnjake, otvorene letnje kuhinje, natkrivene prostore pergolama i slično.

Sa odabranom lokacijom, glavni izazov prilikom usvajanja koncepta i projektovanja samog objekta je adekvatan raspored prostorija tako da spavaće sobe i zajedničke prostorije za odmor budu pozicionirane na način koji omogućava da svaka od njih ima prirodno osvetljenje i ventilaciju [3].

Unutrašnjost ovih vila mora parirati njihovoj spoljašnjosti, pa se tako unutra moraju naći prirodni materijali, tople boje i tonovi. Igra svetlosti i senke mora biti u potpunoj ravnoteži i ništa ne treba previše da odvlači pažnju gostima ovakvih kuća, već je neophodno da svaki detalj upotpuni mir i odmor gostiju.

Prateći trendove $u$ razvoju enterijera poželjno je bilo korišćenje neutralnih boja, zadržavanje klasične arhitekture i starinskog šarma koji se ogleda u upotrebi materijala kao što su drvo i kamen. Odabir podnih obloga takođe je uticalo kako na ambijent, tako i na izolaciju od buke i pružanje udobnosti. Podovi ostavljaju vrlo važan vizuelni utisak prilikom ulaska u neku prostoriju, i oni mogu značajno ulepšati enterijer.

Prilikom enterijerskog opremanja treba težiti upotrebi nameštaja od svetlog drveta, jer vizuelno ne opterećuje prostor, a posebno se preporučuje za male stanove i prostorije. Osim toga, uz svetao drveni nameštaj zidovi, slike i dekoracija dolaze više do izražaja.

Drvo je podjednako zastupljeno i u vidu različitih detalja i ukrasnih elemenata koji obogaćuju enterijer. Interesantne drvene komode, police za knjige, posebno dizajnirani ramovi za zidne i stone fotografije, interesantni elementi za sedenje, kao i razne drvene figurice nezaobilazni su drveni detalji koji će dodatno doprineti osećaju topline i prijatnosti. Stolice koje su sačinjene od jednog bloka drveta, na primer, predstavljaju popularan dizajn u svakom okruženju. Slični komadi mogu biti dizajnirani i prilagođeni kako bi se savršeno uklapali u bilo koji dekor. Istraživanjem se dolazi do toga da je za ovakvu vrstu objekta najpovoljniji raspored u kom bi se na spratu odvojili smeštajni kapaciteti od zajedničkih prostorija sa pratećim sadržajima koji bi se nalazili u prizemlju.

U zavisnosti od mogućnosti i samog prostora u prizemlju je potrebno predvideti ulazni predprostor, kuhinju i slično. Prostor za smeštaj gostiju mora biti adekvatno enterijerski opremljen. Svi apartmani moraju imati pripadajući toalet, terasu sa primerenim pogledom, ili ukoliko ne postoji mogućnost otvaranja prohodne terase izrada francuskih balkonaca.

\subsection{KONCEPT}

Objekat je arhitektonski oblikovan tako da su od postojeće kuće bruto površine $734 \mathrm{~m} 2$ projektovana dva nezavisna objekta - objekat A spratnosti P+1 i objekat B spratnosti P.

Konceptualna ideja je da se u okviru objekta A napravi smeštajni deo, sa zajedničkim prostorijama i pratećim sadržajima, dok bi se objekat B, koji trenutno nema namenu, pretvorio u kafeteriju koji bi koristili i ostali posetioci kompleksa.

Prema novoprojektovanom programu, isprojektovana su dva bazena, jedan veći i jedan manji bazen. Obezbeđen je kolski pristup objektu, kao i veći broj parking-mesta.

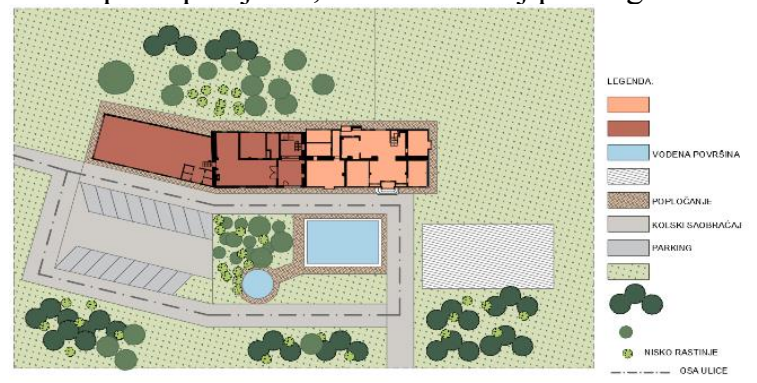

Slika 3: Prikaz situacije kompleksa

U okviru objekta A, u prizemlju ovog komlepksa nalazi se ulazni hol, prostrana trpezarija i mala kuhinja. Svaka od tih prostorija stvara vezu sa centralnim i najbitnijim prostorom, a to je prostor za odmaranje. Da bi se održala toplina ovog prostora, neki elementi starog prostora su zadržani grede, koje stvaraju rustičnu atmosferu, a u pojedinim sobama su sačuvane podne obloge koje doprinose „mekoći” ambijenta.

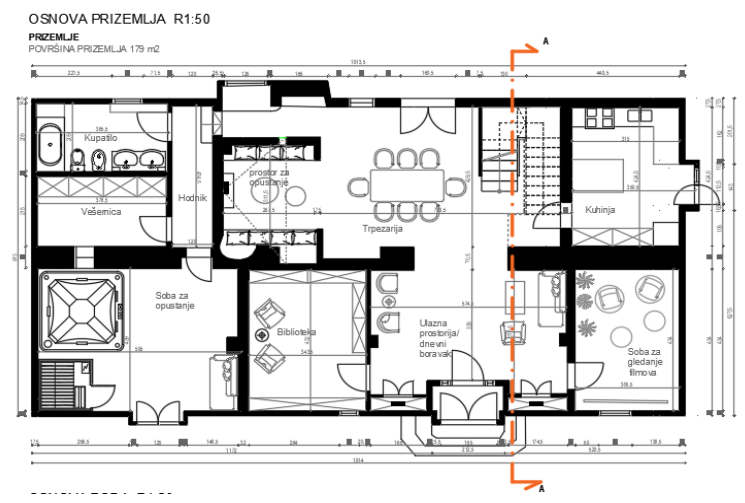

Slika 4: Prikaz osnove vile 
Prvi sprat objekta A predviđen je za spavanje gostiju ovog kompleksa. Pored spavaćih soba, ovaj sprat ima dodatni dnevni boravak, koji je malo privatniji u osnosu na dnevni boravak prizemne etaže. Osim dnevnog boravka, u ovoj etaži su tri master sobe.

Stupanjem u ulazni hol, bilo je potrebno zadržati otvorenost ove prostorije, kako bi gosti vile imali što ugodniji i prijatniji doček. U ovoj celini, pored ulazne zone, sa desne i leve strane su dve prostorije koje su namenjene za relaksaciju, slika 4.

Iz ulaznog hola direknom komunikacijom stiže se do trpezarije i prostora za opuštanje, suštinski najvažnije prostorije. Iz trpezarije neposredno se prilazi kuhinji, koja je odvojena od centralnog prostora, ali druge strane ima direktnu vezu sa prostorom.

U prizemlju se nalazi kupatilo, vešernica i prostor za odmor koji ima direktan izlaz na dvorište sa bazenom. Stepenišnom komunikacijom ulazi se u dnevnu sobu, koja je zarad postizanja privatnosti smeštena na gornji sprat. Iz nje se odmah može doći do drugih soba, odnosno do master soba.

Zaključno, na spratu postoje tri sobe, od kojih svaka ima svoje kupatilo.

Dodatni objekat koji trenutno nema namenu trebalo je pretvoriti u malu kafeteriju i malu menzu koju mogu da koriste i ostali posetioci ovog kompleksa koji su došli da koriste ostale sadržaje.

Prilikom pronalaska programskog rešenja ovog objekta najrelevantnije je bilo zadržati prostranost, kako bi se gosti kafeterije osećali ugodnije. Pored postojećih prostorija, u glavnom delu kafeterije izgrađen je toalet koji može da primi više gostiju.

Ulaz u kafeteriju moguć je sa dve strane, kroz glavni hol i ulaskom u magacinski prostor, koji koriste samo zaposleni ovog kompleksa. Pored ovih prostorija tu je i magacinski prostor, kancelarija i toalet za zaposlene.

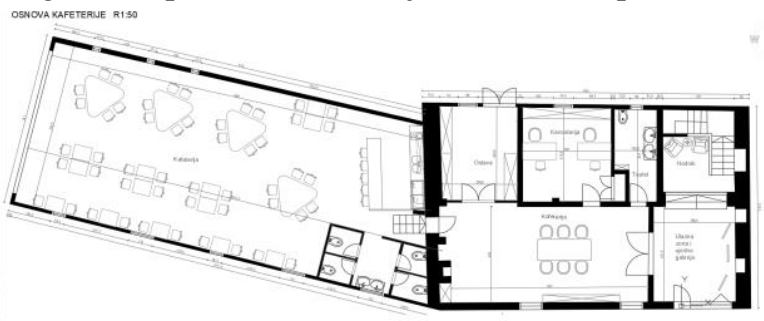

Slika 4: Prikaz osnove kafeterije

\subsection{TRPEZARIJA I PROSTOR ZA OPUŠTANJE}

Primarni elementi ovog prostora su grede koje su ostavljene u postojećem stanju da bi se sačuvao osnovni utisak ambijenta. Kameni pod je takođe sačuvan u ovom enterijeru. Pored materijala za zidnu i podnu oblogu, akcenat je na ručno rađenom nameštaju. Jednostavnost $i$ minimalistički dodaci najvažniji su u ovom arealu, slika 5 .

Prostorija je osvetljena prirodnim i veštačkim osvetljenjem. Veštačko osvetljenje je sačinjeno od visećih lampi i led panela koji su i u ostalim prostorijama. Visilice od prirodnog materijala se nalaze iznad trpezarijskog stola i prostora za opuštanje.
Lagani materijali i letnje boje, neutralni tonovi, upareni sa cvećem i nekom vrstom zelenila unose toplinu $u$ savremen dom.

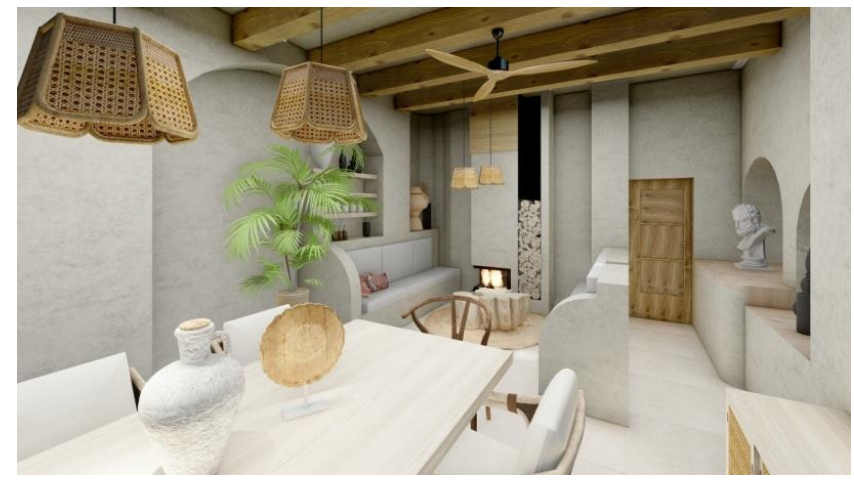

Slika 5: Prikaz enterijera trpezarije i prostora za opuštanje

\subsection{KUPATILA I SPAVAĆE SOBE}

U trpezariji i u prostoru za odmor vile, u kupatilima i spavaćim sobama sačuvane su grede, kameni podovi i zidovida bi se zadržao originalni stil. Hladan materijal uparen je sa toplim, odnosno, primarno, kombinovani su kamen, drvo i noviji materijali, kao što je mesing. Ovde postoje viseće lampe od pletenog materijala koje daju optimalnu svetlost za ovaj prostor. Bela boja dominira, ne bi li se prostor otvorio, slika 6 i 7 .

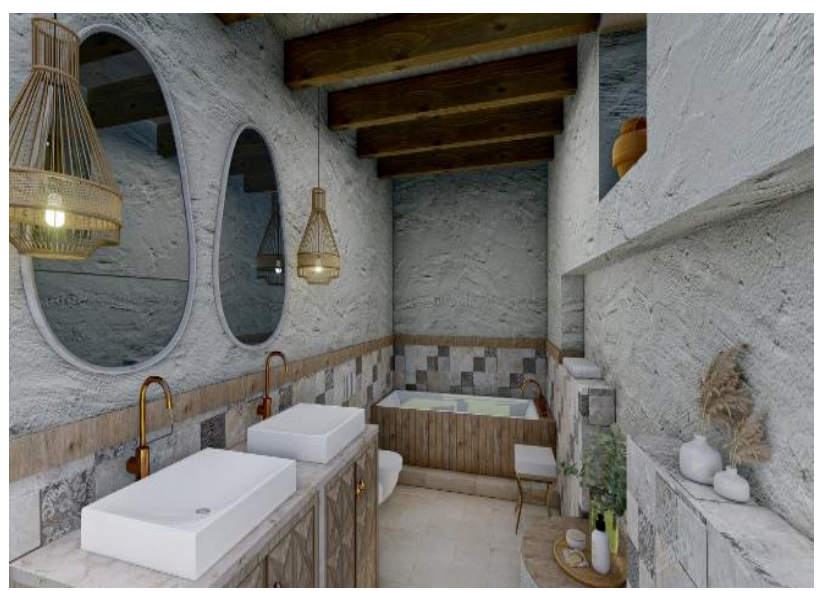

Slika 6: Prikaz enerijera kupatila

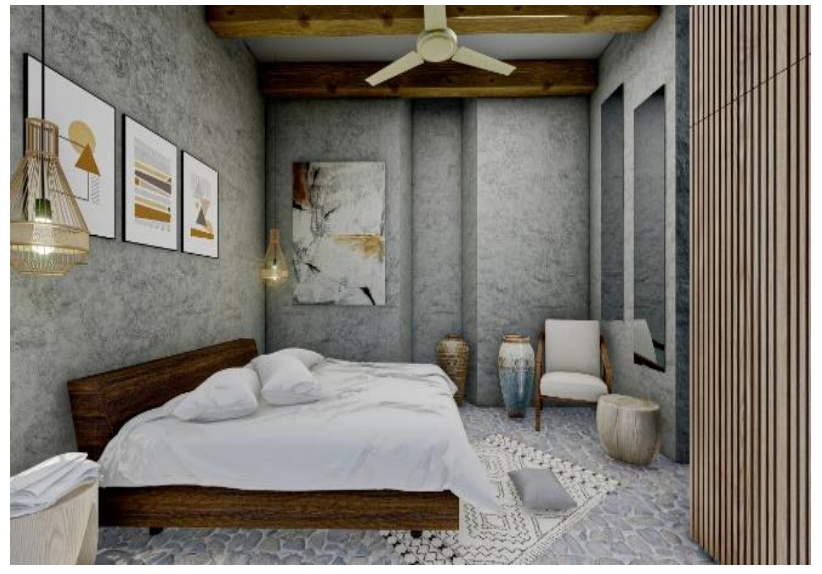

Slika 7: Prikaz enterijera spavaće sobe 


\section{KAFETERIJA}

U pomoćnom objektu vile imamo smeštenu prelepu prostranu kafeteriju koja je kao sto sam već u konceptu napomenula ne samo za korisnike vile već i za goste koji su došli na jednodnevni odmor i poseti ovom kompleksu. Pravilima osmiljavanju ovog enterijera su važila kao i u prethodnim prostorijama. Gde sam postojeće dobro očuvane elemente sačuvala.

Gde sam postojeće dobro očuvane elemente sačuvala Prilikom osmišljavanja enterijera želja mi je bila da na prvi pogled vuče na mediteransku arhitekruru.

Korišćenjem pletenih visilica i drvenih elemenata ovaj prostor je dobio topliju atmosferu. Dovoljan broj mesta za sedenje čine ovaj kompleks bogatijim i dozvoljava veću mogućnost posetilaca.

Prilikom osmišljavanja enterijera koristile su se dizajnerske stolice Jem Lounge stolica i Moris stolica koji upotpunjuju ovaj prostor.

Pletene i drvene visilice daju prostoru romantičnu atmosferu. U prostor je uvedena i mrežasto staklo koje je ujedinjeno sa novim prozorima i izlozima koji su osmišljeni i time ih čini ujedinjenim.

Dodatnu atmosferu prostoru daju biljni elementi koji su ubačeni po zidovima i čine ovaj prostor toplijim. Spuštanjem parapeta prozora na 0 dobijamo veću osvetljenost prostoru, veću površinu prirodnog osvetljenja i time dobijamo utisak da se stapamo sa prirodom, slike 8, 9, 10.

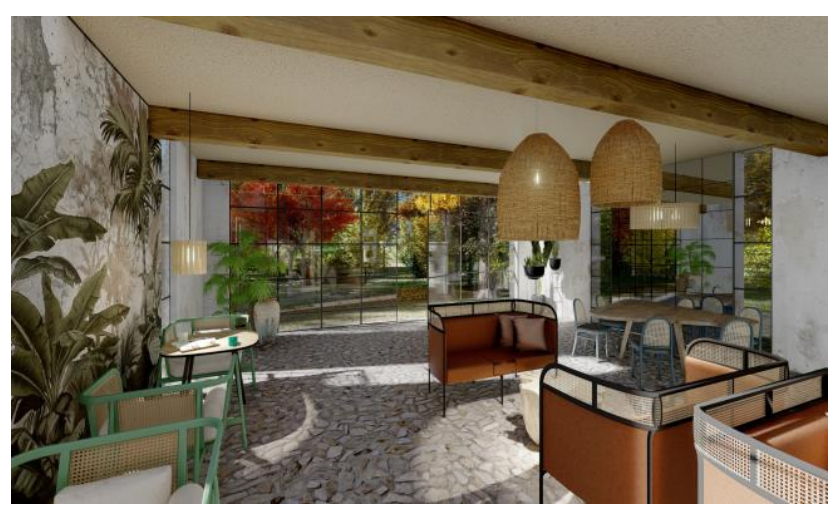

Slika 8: Enterijer kafeterije

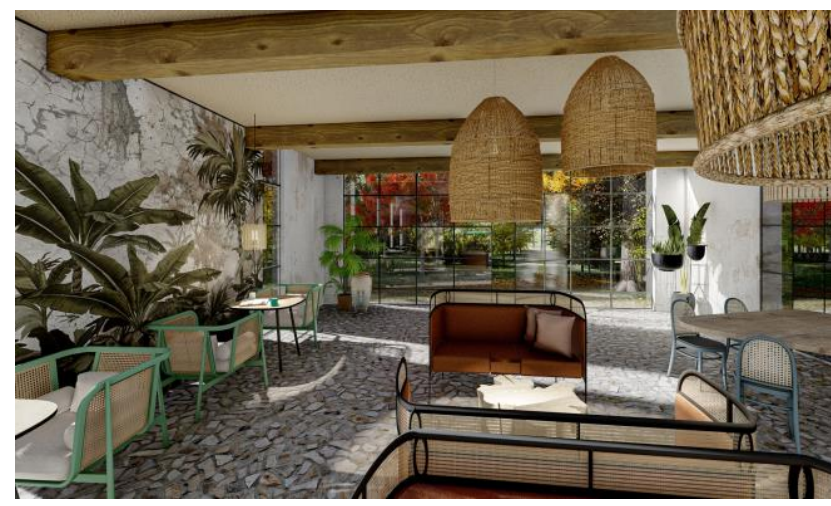

Slika 9: Enterijer kafeterije

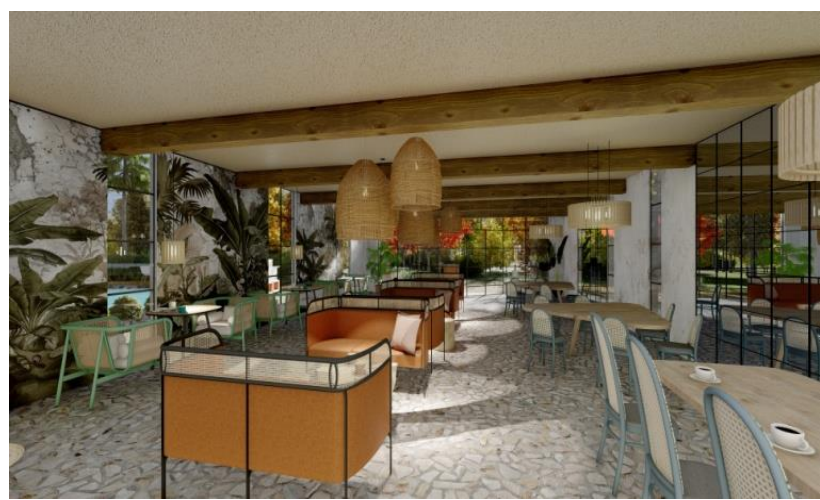

Slika 10: Enterijer kafeterije

\section{ZAKLJUČAK}

Projektnim rešenjem dobijen je moderni objekat za opuštanje i relaksaciju. Savršena lokacija dozvolila da je da on ima odlličan turistički potencijal, pa je u skladu sa tim napravljen i objekat za ugošćavanje

ostalih posetilaca koji objekat ne bi iznajmljivali, već bi samo uživali u njegovim propratnim sadržajima.

Trpezarija, bazeni, bašta, pogled, sve su to činioci koji su uticali na ideju da se na pomenutoj lokaciji napravi takav objekat. Kroz ceo koncept, najvažnije je bilo održati autohtoni duh mesta na kojem vila stoji, ali naći najbolji mogući način da njen enterijer ipak ide u korak sa modernim vremenom i minimalističkim stilom kojem se u isto vreme težilo. Zato je trebalo zadržati određene detalje kao što su grede, zidne obloge, pod, vrata, prozori, pa čak i neki zatečeni nameštaj pogodan za restauraciju. Paleta boja je neutralna, nenapadna, upravo onakva kakva treba da bude u prostorima koji služe za odmor i relaksaciju.

Ovako uređen objekat trebalo bi da predstavlja pravo mesto gde bi čovek želeo da nađe mir od hektičnog gradskog života, i sigurno je mesto gde bi se ponovo vraćao.

\section{LITERATURA}

[1] https://www.casaolivi.com/

[2] http://www.villakalos.com/

[3] Projektni zadatak, Idejno. Rešenje vile i kafeterije

\section{Kratka biografija:}

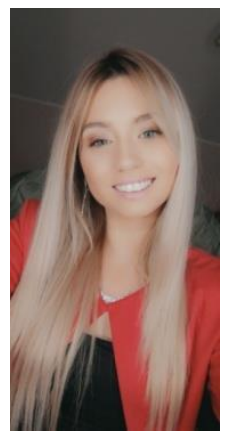

Ivana Šanjević rođena je u Manhajmu 1995. god. Osnove studije arhitekture na Fakultetu tehničkih nauka je upisala 2014. godine, a završila 2018. Iste godine upisuje master smer na Fakultetu tehničkih nauka - Dizajn enterijera. kontakt: ivanasanjeic95@gmail.com 